\title{
Lipid-linked Intermediates and the Synthesis of Acetan in Acetobacter xylinum
}

\author{
By NORA IÑON DE IANNINO, ROBERTO O. COUSO AND \\ MARCELO A. DANKERT* \\ Instituto de Investigaciones Bioquimicas 'Fundacion Campomar', \\ Facultad de Ciencias Exactas y Naturales and \\ Consejo Nacional de Investigaciones Cientificas y Tecnicas, \\ Antonio Machado 151, (1405) Buenos Aires, Argentina
}

(Received 22 December 1987)

\begin{abstract}
Several strains of Acetobacter xylinum were screened for in vivo cellulose and acetan production, and for in vitro synthesis of a prenyl-diphosphate-hexasaccharide, using UDP-Glc, UDP-GlcA and GDP-Man as sugar donors. The lipid-bound saccharide was synthesized only by acetanproducing strains. Previous work has shown that the in vitro-synthesized lipid-linked saccharides have the same structure as the acetan repeating unit. The present results strongly suggest a precursor-product relationship. The strains that produced acetan lost their ability to do so by ageing of the culture.
\end{abstract}

\section{INTRODUCTION}

Acetobacter xylinum is a Gram-negative organism, which characteristically synthesizes cellulose. Couso et al. (1987) reported that strain B42 also produces acetan, a complex exopolysaccharide containing glucose, mannose, glucuronic acid and rhamnose in a molar ratio of $4: 1: 1: 1$. The proposed structure is represented in Fig. 1. Furthermore, previous work from this laboratory has shown that EDTA-treated cells of $A$. xylinum B42 are able to synthesize in vitro a lipid-linked heptasaccharide having the same structure as the repeating unit of acetan (Fig. 1, solid frame) suggesting a precursor-product relationship. The step-wise assembly of the heptasaccharide on a diphosphate prenol was obtained using UDP-Glc, GDP-Man, UDPGlcA and TDP-Rha as sugar donors, and all the compounds formed at the different intermediate steps were isolated and characterized (Garcia et al., 1974; Couso et al., 1980, 1982). However, all attempts to obtain the in vitro polymerization of the lipid-linked heptasaccharide in order to synthesize acetan (Fig. 2) were unsuccessful.

In the present work several strains of $A$. xylinum have been screened for in vivo production of cellulose and acetan, and for in vitro accumulation of prenyl-diphosphate-hexasaccharide, the lipid intermediate, which is easier to characterize (Couso et al., 1982). In addition, it is shown that both the in vivo synthesis of acetan and the in vitro formation of a lipid-linked hexasaccharide may be irreversibly lost by ageing of the culture.

\section{METHODS}

Chemicals. UDP- $\left[{ }^{14} \mathrm{C}\right] \mathrm{Glc}\left(200-309 \mathrm{Ci} \mathrm{mol}^{-1} ; 7 \cdot 4-11.4 \mathrm{GBq} \mathrm{mol}^{-1}\right)$ and UDP- $\left[{ }^{14} \mathrm{C}\right] \mathrm{GlcA}\left(200-309 \mathrm{Ci} \mathrm{mol}^{-1}\right.$; 7.4-11.4 G Bq mol${ }^{-1}$ ) were prepared as described by Garcia et al. (1974) and Couso et al. (1980). All other chemicals were commercial products.

Bacterial strains and culture media. Cellulose-forming Acetobacter xylinum strains were NRRL B42 and ATCC 10821, 23769 and 10245. Strain NCIB 8747 does not produce cellulose. All these strains were purchased from the American Type Culture Collection. Strain RCGr1 was isolated from plates of B42 as a mucoid and relatively large colony $\left(2 \cdot 0-2.5 \mathrm{~mm}\right.$ in diameter after one week at $\left.28^{\circ} \mathrm{C}\right)$. Strain NICh1 was isolated from RCGrl cultures; it produces small dry colonies $\left(0.5-1.0 \mathrm{~mm}\right.$ diameter after one week at $\left.28^{\circ} \mathrm{C}\right)$. 


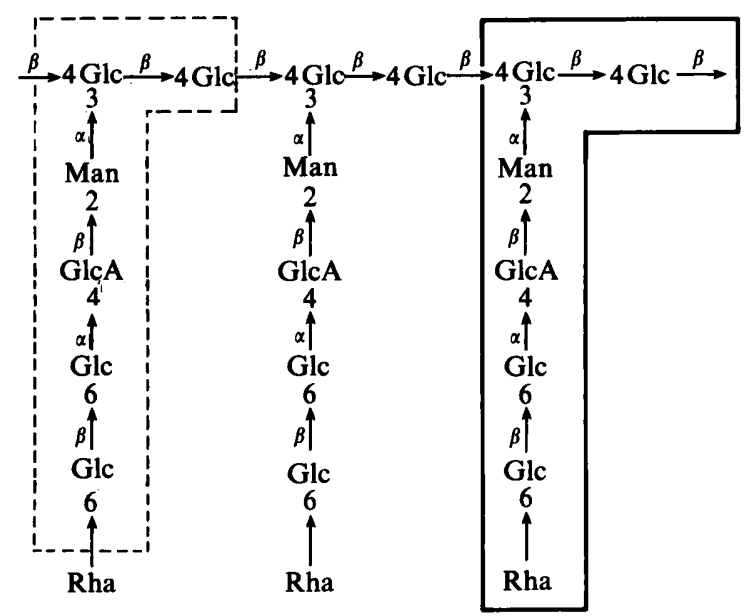

Fig. 1. Proposed structure for acetan (Couso et al., 1987). The solid frame indicates the repeating unit. The broken frame shows the $X_{6}$ hexasaccharide.

The liquid and solid media developed by Hestrin \& Schramm (1954) were used.

Enzyme system. Cellulose-producing cells were grown in unshaken cultures and freed from cellulose by filtering through cheesecloth as described by Hestrin \& Schramm (1954), with slight modifications. The cell suspension filtrates were centrifuged and acetan was isolated from the supernatants (see below). Strain 8747 was grown with rotary shaking ( 200 r.p.m.) at $28^{\circ} \mathrm{C}$ and the filtration step was omitted. The cell pellets, washed and treated with EDTA as previously reported (Garcia et al., 1974), were used as enzyme source.

Protein was determined by the Lowry method, with bovine serum albumin as standard.

Cellulose. The cellulose fibres retained in the cheesecloth as described above were removed, treated with alkali and washed as reported by Hestrin \& Schramm (1954). They were dried in vacuo after washing first with ethanol and then with diethyl ether. Cellulose production was expressed as $\mathrm{mg}$ dried cellulose (mg wet cells) ${ }^{-1}$.

Acetan. $\mathrm{KCl}$ was added to the culture supernatants to give a final concentration of $1 \%(\mathrm{w} / \mathrm{v})$. The polysaccharide was precipitated by adding 2 vols $96 \%$ (v/v) ethanol. The precipitate was dissolved in distilled water, reprecipitated three times, dialysed and lyophilized as in previous work (Couso et al., 1987). This preparation was protein-free, as judged by the Lowry method. Yields were expressed as mg dried material (mg wet cells) ${ }^{-1}$.

Incubations. Standard assays were done in $70 \mathrm{mM}$-Tris/HCl buffer pH 8.2, with EDTA-treated cells $(200-500 \mu \mathrm{g}$ protein), $8 \mathrm{mM}-\mathrm{MgCl}_{2}, 0.035 \mathrm{mM}$-GDP-Man, $0.035 \mathrm{mM}-\mathrm{UDP}-\mathrm{GlcA}$ and $0.010 \mathrm{mM}-\mathrm{UDP}-\left[{ }^{14} \mathrm{C}\right] \mathrm{Glc}$. When UDP$\left[{ }^{14} \mathrm{C}\right.$ ] GlcA $(0.010 \mathrm{mM})$ was used, the UDP-Glc concentration was $0.350 \mathrm{mM}$. TDP-Rha, the donor of the last sugar of the repeating unit, was not added in this study since its absence did not alter the results (Couso et al., 1982). The reactions were performed in a final volume of $0.070 \mathrm{ml}$ at $30^{\circ} \mathrm{C}$ for $30 \mathrm{~min}$, stopped by addition of a fourfold molar excess of EDTA over the $\mathrm{Mg}^{2+}$ concentration and centrifuged at $6000 \mathrm{~g}$ for $5 \mathrm{~min}$. The cell pellets were washed three times with $1 \mathrm{ml} 7.0 \mathrm{mM}$-Tris/HCl buffer $\mathrm{pH} 8.2$ and extracted three times with $0.1 \mathrm{ml}$ chloroform/methanol/ water (1:2:0.3, by vol.) (1203 solvent). Radioactivity incorporated into the 1203 extract was counted in Bray's solution (Bray, 1960), with a Packard Tri-Carb scintillation counter.

In incubations done with UDP- $\left[{ }^{14} \mathrm{C}\right] \mathrm{Glc}$, unlabelled UDP-GlcA and GDP-Man as sugar donors and enzyme from B42 cells, under the standard conditions used, the main product extracted with 1203 solvent is $X_{6}$ hexasaccharide-diphosphate-prenol (Couso et al., 1982), but small amounts of a neutral glucan which is also formed may be present (Garcia et al., 1974). To separate these two components, the 1203 extracts were hydrolysed in $0.01 \mathrm{M}-\mathrm{HCl}$ at $100^{\circ} \mathrm{C}$ for $10 \mathrm{~min}$ and submitted to paper electrophoresis with $1.2 \mathrm{M}$-pyridinium acetate buffer pH 6.5 as previously desscribed (Couso et al., 1982). Under these mild hydrolysis conditions only the phosphate linkages are split (Fig. 2), releasing the labelled $X_{6}$ hexasaccharide (Fig. 1) which is readily characterized by its electrophoretic mobility $\left(R_{\mathrm{UMP}}=0.5\right)$ (Couso et al., 1982). The glucan is not affected by this treatment and remains in the neutral area of the electrophoretogram. The relative amounts of neutral and charged compounds were calculated from the respective peak areas.

\section{RESULTS}

\section{Correlation between in vivo acetan production and in vitro accumulation of lipid-linked sugars}

The in vivo synthesis of acetan and cellulose was investigated in the different strains of $\boldsymbol{A}$. xylinum (Table 1). The only strains that produced acetan were B42 and its derivative RCGr1, 


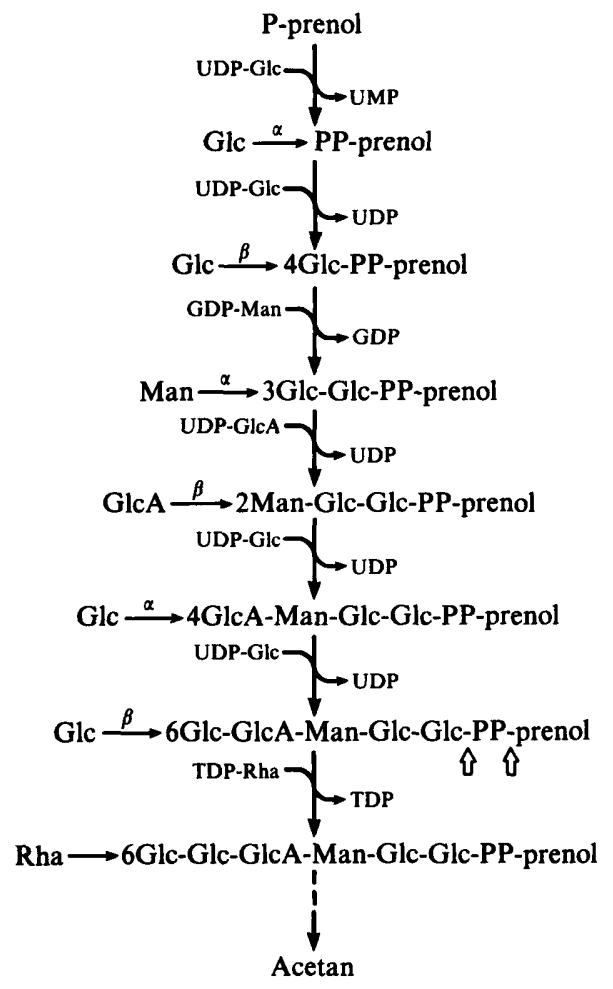

Fig. 2. Proposed scheme for the stepwise assembly of the $X_{7}$ heptasaccharide-diphosphate-prenol (Couso et al., 1982). The empty arrows in the lipid-linked $X_{6}$ hexasaccharide indicate the linkages labile to mild acid hydrolysis $\left(0.01 \mathrm{M}-\mathrm{HCl}, 100^{\circ} \mathrm{C}\right.$, for $\left.10 \mathrm{~min}\right)$. The dashed arrow indicates the proposed polymerization step leading to the formation of acetan.

Table 1. Comparison between in vivo polysaccharide production and in vitro synthesis of lipid-linked hexasaccharide

\begin{tabular}{|c|c|c|c|c|c|c|}
\hline \multirow[b]{4}{*}{ Strain } & & & \multicolumn{4}{|c|}{ Radioactivity incorporated in vitro into $1203^{*}$ extract } \\
\hline & \multirow{2}{*}{\multicolumn{2}{|c|}{$\begin{array}{c}\text { In vivo production } \\
{\left[\mathrm{mg}(\mathrm{mg} \text { wet cells })^{-1}\right] \text { of: }}\end{array}$}} & \multirow{3}{*}{$\begin{array}{c}\text { From }\left[{ }^{14} \mathrm{C}\right] \mathrm{GlcA} \\
\text { C.p.m. } \\
\text { (mg protein) }^{-1}\end{array}$} & \multicolumn{3}{|c|}{ From [ ${ }^{14} \mathrm{C}$ ]glucose: } \\
\hline & & & & Total c.p.m. & Hexasaccharide & Neutral \\
\hline & Acetan & Cellulose & & (mg protein) $)^{-1}$ & $(\%)$ & $(\%)$ \\
\hline B42 & $0 \cdot 27$ & $0 \cdot 37$ & 20870 & 85700 & $89 \cdot 5$ & $10 \cdot 5$ \\
\hline RCGrl & $0 \cdot 30$ & $0 \cdot 30$ & 27710 & 125700 & $92 \cdot 6$ & $7 \cdot 4$ \\
\hline NIChl & - & $1 \cdot 22$ & 925 & 2300 & - & 100 \\
\hline 10821 & - & $0 \cdot 32$ & 288 & 2050 & - & 100 \\
\hline 23769 & - & 0.41 & $5640 \dagger$ & 2600 & - & 100 \\
\hline 10245 & - & $0 \cdot 16$ & 100 & 1900 & - & 100 \\
\hline 8747 & - & - & $3000+$ & 800 & - & 100 \\
\hline
\end{tabular}

- , Not detected.

* 1203, chloroform/methanol/water ( $1: 2: 0 \cdot 3$, by vol.).

+ This material was characterized as a lipid-linked glucuronide of unknown function, identical to that obtained with enzyme from strain B42 and UDP- $\left[{ }^{14} \mathrm{C}\right] \mathrm{GlcA}$ as the only sugar donor (Couso et al., 1982, 1986). This glucuronide was not detected when the incubations were performed in the presence of the three donors either using B42 or RCGr1 enzymes. 
Table 2. Effect of ageing on synthesis of polysaccharide and lipid-linked sugar

\begin{tabular}{|c|c|c|c|c|c|}
\hline \multirow[b]{2}{*}{ Strain } & \multirow{2}{*}{$\begin{array}{l}\text { Age of } \\
\text { culture* }\end{array}$} & \multirow{2}{*}{$\begin{array}{l}\text { Size of } \\
\text { colony } \\
\text { selected }\end{array}$} & \multicolumn{2}{|c|}{$\begin{array}{c}\text { In vivo production } \\
{\left[\mathrm{mg}(\mathrm{mg} \text { wet cells) })^{-1}\right] \text { of: }}\end{array}$} & \multirow{2}{*}{$\begin{array}{l}\text { In vitro incorporation } \\
\text { of }\left[{ }^{14} \mathrm{C}\right] \mathrm{GlcA} \\
\text { into } 1203 \dagger \text { extract } \\
\left.\text { [c.p.m. }(\mathrm{mg} \text { protein })^{-1}\right]\end{array}$} \\
\hline & & & Acetan & $\overbrace{\text { Cellulose }}$ & \\
\hline RCGrl & Fresh & Large & $0 \cdot 31$ & $0 \cdot 30$ & 21100 \\
\hline RCGrl & Old & Large & 0.29 & $0 \cdot 32$ & 21800 \\
\hline RCGrl & Old & Small & - & 0.78 & 1000 \\
\hline NIChl & Fresh & Small & - & 0.80 & 800 \\
\hline NIChl & Old & Small & - & 0.85 & 640 \\
\hline
\end{tabular}

- , Not detected.

* 'Fresh' and 'old' cultures were agar plates grown for $7 \mathrm{~d}$ and for $45 \mathrm{~d}$, respectively. In each case a colony with the morphology indicated was selected and cultivated in unshaken cultures for $7 \mathrm{~d}$ to obtain the polysaccharides and the enzyme preparations.

$\dagger 1203$, chloroform/methanol/water (1:2:0.3, by vol.).

which formed cellulose also, The other strains tested produced cellulose but not acetan, except for strain 8747 , which did not synthesize either polysaccharide.

These results were compared with the in vitro capacity to accumulate lipid-linked $\mathbf{X}_{6}$ hexasaccharide, a probable precursor of acetan (Fig. 1, broken frame, and Fig. 2). These assays, done using either UDP- $\left[{ }^{14} \mathrm{C}\right] \mathrm{GlcA}$ or UDP- $\left[{ }^{14} \mathrm{C}\right] \mathrm{Glc}$, showed that only the two acetanproducing strains were also able to synthesize lipid-linked hexasaccharide in vitro (Table 1).

The relatively high incorporations of $\left[{ }^{14} \mathrm{C}\right] \mathrm{GlcA}$ observed with strains 23769 and 8747 are due to the formation of a lipid-linked glucuronide identical to that already described for strain B42 (Couso et al., 1986). With enzyme preparations from strain B42 this glucuronide is obtained in incubations done with UDP- $\left[{ }^{14} \mathrm{C}\right] \mathrm{GlcA}$ as the only sugar donor; if unlabelled UDP-Glc and GDP-Man are also present in the incubation mixture, $\left[{ }^{14} \mathrm{C}\right] \mathrm{GlcA}$ is only incorporated into the $\mathrm{X}_{6}$ hexasaccharide-diphosphate-prenol and the formation of lipid-linked [ $\left.{ }^{14} \mathrm{C}\right]$ glucuronide is negligible. This is not the case for strains 23769 and 8747, which cannot synthesize $X_{6}$ hexasaccharide-diphosphate-prenol. The lipid-linked $\left[{ }^{14} \mathrm{C}\right]$ glucuronide does not participate in $X_{6}$ hexasaccharide biosynthesis and its function is unknown (Couso et al., 1982). It is insoluble in water but soluble in butanol and other organic solvents. Mild acid $\left(0.01 \mathrm{M}-\mathrm{HCl}, 100{ }^{\circ} \mathrm{C}\right.$, for $10 \mathrm{~min})$ or mild alkaline $(0.06 \mathrm{M}-\mathrm{NaOH}$, at room temperature for $5 \mathrm{~min})$ hydrolysis releases free $\left[{ }^{14} \mathrm{C}\right] \mathrm{Glc} A$ (Couso et al., 1986).

Similarly the $\left[{ }^{14} \mathrm{C}\right]$ glucose incorporation observed with strains other than B42 and RCGr1 was due to the formation of an electrophoretically neutral compound: not even traces of the $X_{6}$ hexasaccharide were detected. This neutral compound was probably a glucan similar to that observed with strain B42, (see Methods). The small amounts of radioactivity present in this fraction did not permit a more detailed study.

\section{Isolation of strains that do not produce acetan}

During this study, in addition to the large, slightly mucoid colonies characteristic of strain RCGrl, small opaque colonies were often detected in cultures from old plates of this strain. On plates inoculated with material from old large colonies (more than $40 \mathrm{~d}$ at $28^{\circ} \mathrm{C}$ ), small colonies were always detectable after $7 \mathrm{~d}$ incubation at $28^{\circ} \mathrm{C}$. This procedure could be repeated several times, starting always with an inoculum from an old large colony: after one week at $28^{\circ} \mathrm{C}$ small colonies were observed. No such small colonies were observed when starting with fresh large colonies (5-7 d old). On the other hand, small-colony strains (such as NIChl) never reverted to the large-colony type.

The ability to produce acetan and cellulose in vivo, and to synthesize lipid-linked hexasaccharide in vitro, was investigated in cultures from RCGr1 and NICh1 colonies of different size and age (Table 2). Only the RCGr1 large colonies were able to produce acetan and lipid-linked intermediates. Small colonies, either from the NICh1 strain or newly obtained from the old RCGrl colonies, were unable to produce acetan and lipid-linked intermediates. Small colonies, on the other hand, systematically produced more cellulose than did the respective large mother colony. 


\section{DISCUSSION}

The in vitro accumulation of lipid-linked saccharides with the structure of the repeating unit of the respective complex exopolysaccharides produced has been described for systems from Acetobacter xylinum (Couso et al., 1982), Rhizobium meliloti (Tolmasky et al., 1982), Agrobacterium tumefaciens (Staneloni et al., 1984), Rhizobium trifolii (Bossio et al., 1986), Aerobacter aerogenes (Troy et al., 1971) and Xanthomonas campestris (Ielpi et al., 1981). However, only in the two latter cases has the polymerization step, leading to the formation of the exopolysaccharide, been described in vitro.

For the Acetobacter xylinum system the present results provide evidence for the assumption that the prenylphosphosugars described in previous papers (Garcia et al., 1974; Couso et al, $1980,1982)$ are intermediates in the biosynthesis of acetan. Only the strains able to produce acetan in vivo (B42 and $\mathrm{RCGr}$ ) are able to synthesize lipid-linked $\mathrm{X}_{6}$ hexasaccharide in vitro (Table 1). The biosynthetic mechanism proposed (Fig. 2) is similar to that reported for Aerobacter and Xanthomonas but different from the one recently described in Acetobacter xylinum for the production of cellulose, in which lipid-linked intermediates do not participate (Ross et al., 1986). Since acetan can be considered as a substituted cellulose it is remarkable that the same organism has different machinery for producing two structurally related exopolysaccharides. It could be argued that homopolysaccharides like cellulose do not need to preassemble repeating units on prenyl derivatives, and can be produced by the classical stepwise addition of the corresponding monosaccharides. But this is not the case for the well-studied systems that make another exo-homopolysaccharide, namely the polysialic capsular polysaccharide from Escherichia coli (Troy et al., 1975) and Neisseria meningitidis (Masson \& Holbein, 1985), in which the participation of prenyl-linked intermediates has been clearly established.

The fact that most $A$. xylinum strains we tested do not produce acetan, and that in those which do the ability to produce it may be lost in old cultures (Table 2), may explain the failure of other groups to detect in vitro synthesis of lipid-linked sugars in other strains (Delmer, 1983).

The authors are indebted to Dr Sara Goldemberg for critically reading this manuscript and to Miss Susana Raffo and Marta Bravo for their excellent technical assistance in the preparation of labelled sugar nucleotides. M.A.D. is a Career Investigator of the Consejo Nacional de Investigaciones Cientificas y Tecnicas (Argentina).

\section{REFERENCES}

Bossio, J. C., Iñon de IANNino, N. \& DANKert, M. A. (1986). In vitro synthesis of a lipid-linked acetylated and pyruvylated oligosaccharide in Rhizobium trifolii. Biochemical and Biophysical Research Communications 134, 205-211.

Bray, G. A. (1960). A simple efficient liquid scintillator for counting aqueous solutions in a liquid scintillation counter. Analytical Biochemistry 1, 279285.

Couso, R. O., IElPI, L., Garcia, R. C. \& DANKERT, M. A. (1980). Synthesis of mannosyl cellobiose diphosphate prenol in Acetobacter xylinum. Archives of Biochemistry and Biophysics 204, 434443.

Couso, R. O., Ielpi, L., Garcia, R. C. \& Dankert, M. A. (1982). Biosynthesis of polysaccharides in Acetobacter xylinum. Sequential synthesis of a heptasaccharide diphosphate prenol. European Journal of Biochemistry 123, 617-627.

Couso, R. O., Iñon de Iannino, N., Garcia, R. C. \& DANKERT, M. A. (1986). Characterization of a lipidglucuronic acid derivative in Acetobacter xylinum preparations. Anales de la Asociacion Quimica Argentina 74, 783-793.

Couso, R. O., IELPI, L. \& Dankert, M. A. (1987). A xanthan gum-like polysaccharide from Acetobacter xylinum. Journal of General Microbiology 133, 21232135.

DELMER, D. P. (1983). Biosynthesis of cellulose. Advances in Carbohydrate Chemistry and Biochemistry 41, 105-153.

Garcia, R. O., Recondo, E. \& Dankert, M. A. (1974). Polysaccharide biosynthesis in Acetobacter xylinum. Enzymatic synthesis of lipid diphosphate and monophosphate sugars. European Journal of Biochemistry 43, 93-105.

Hestrin, S. \& Schramm, M. (1954). Preparation of freeze-dried cells capable of polymerizing glucose to cellulose. Biochemical Journal 58, 345-352.

IelPi, L., Couso, R. O. \& DANKert, M. A. (1981). Lipid-linked intermediates in the biosynthesis of xanthan gum. FEBS Letters 130, 253-256.

Masson, L. \& Holbein, B. E. (1985). Role of lipid intermediate(s) in the synthesis of serogroup $B$ Neisseria meningitidis capsular polysaccharide. Journal of Bacteriology 161, 861-867.

Ross, P., Aloni, Y., Weinhouse, H., Michaeli, D., Weinberger-Ohana, P., Mayer, R. \& Benziman, M. (1986). Control of cellulose synthesis in Acetobacter xylinum. A unique guanyl oligonucleotide is the immediate activator of the cellulose synthase. Carbohydrate Research 149, 101-117. 
Staneloni, R. J., Tolmasky, M. E. \& Leloir, L. F. Troy, F. A., Frerman, F. E. \& Heath, E. C. (1971). (1984). Lipid-bound saccharides containing glucose and galactose in Agrobacterium tumefaciens. Journal of General Microbiology 130, 869-879.

Tolmasky, M. E., Staneloni, R. J. \& Leloir, L. F. (1982). Lipid-bound saccharides in Rhizobium meliloti. Journal of Biological Chemistry 257, 67516757.

The biosynthesis of capsular polysaccharide in Aerobacter aerogenes. Journal of Biological Chemistry 2A6, 118-133.

Troy, F. A., ViJay, I. K. \& TESChe, N. (1975). Role of undecaprenol phosphate in synthesis of polymers containing sialic acid in Escherichia coli. Journal of Biological Chemistry 250, 156-163. 